\title{
When permafrost thaws
}

\author{
Thawing permafrost mobilizes concerning amounts of carbon into the wider environment. Piecing together carbon \\ sources and sinks in this complex system is important to understanding its overall climate impact.
}

$\mathrm{Ps}$ ermafrost is one of the world's largest carbon sinks, storing twice as much carbon as the atmosphere ${ }^{1}$. This substantial carbon pool is locked away thanks to the low soil temperature. However, the permafrost zone is warming across the globe $^{2}$, causing frozen soil to thaw. This process is expected to release huge amounts of carbon into the atmosphere, potentially leading to a strong positive feedback that could amplify climate warming. Yet, the magnitude of greenhouse gas (GHG) emissions resulting from thawing permafrost remains uncertain. This is because permafrost thawing drives a diverse range of physical, chemical and biological changes that affect not only the soil, but also broader ecosystems. We need to better understand what happens to soil and the wider environment as permafrost thaws to determine the net effect on the global carbon cycle.

Permafrost warming changes the soil environment, which activates the microbial decomposition of organic matter. Microbial activity is largely suppressed when the temperature is below freezing. However, as the ambient climate warms, frozen soil thaws and microorganisms speed up the decomposition of organic matter into carbon dioxide $\left(\mathrm{CO}_{2}\right)$, methane $\left(\mathrm{CH}_{4}\right)$ and nitrous oxide $\left(\mathrm{N}_{2} \mathrm{O}\right)$. The process can be further accelerated as the microbial community composition changes.

Permafrost soil is lacking biogeochemical processes due to the reduced diversity of the microbial community via environment filtering over millennia-long freezing. These missing processes, however, can be recovered as the community diversity increases in the warmed soil. An Article in this issue shows that easing limitations of biogeochemical functions in permafrost soil makes soil carbon even more vulnerable to decomposition, which increases microbial $\mathrm{CO}_{2}$ production by $38 \%$.

Direct GHG emissions may only account for part of the carbon loss from thawing sites. Much of the carbon is actually taken away by meltwater. Direct measurements of soil carbon change in an experimentally warmed permafrost site in Alaska show that lateral hydrological export of carbon is responsible for more than $50 \%$ of carbon loss during permafrost degradation ${ }^{3}$. Failure to consider the lateral transport of carbon may substantially underestimate the impact of permafrost thaw on climate change.

A considerable amount of the thawed carbon can enter surrounding inland waters, where it will experience more complex physical, chemical and biological processes as it travels to the ocean. Not all of the processes lead to the release of carbon though. For example, burial in sediments, selective preservation and microbial uptake ${ }^{4}$ can sequester carbon in waters and reduce GHG emissions. The thawed carbon may also reach the ocean, where it can persist for long periods of time.

Nevertheless, much of this riverine carbon may still end up in the atmosphere, adding to direct emissions from thawing soils. Much of the organic matter entering inland waters is highly biodegradable, and microbial decomposition results in considerable GHG emissions, especially $\mathrm{CH}_{4}$, a GHG that is much more potent than $\mathrm{CO}_{2}$. Direct measurements of methane emissions from four basins in the Tibetan Plateau permafrost zone - where the rates of permafrost loss are among the highest in the world - show that $\mathrm{CH}_{4}$ emission rates from lakes in the region are six times higher than the global average for streams and rivers 5 . However, it remains unclear to what extent thawing permafrost contributes to these GHG emissions.

The rate at which permafrost thaws can also affect how much carbon is released. Current understanding is mostly based on experiments that simulate gradual thawing. Yet, real-world observations show that thawing can occur much more dramatically. Soils held together by ice can collapse suddenly as permafrost warms, causing land to sink and be flooded by swelling lakes and wetlands ${ }^{6}$. This abrupt thawing process can release up to $190 \%$ more GHG emissions compared to gradual thaw ${ }^{7}$. A model simulating this abrupt thaw predicts that while this type of thaw will only occur in less than $20 \%$ of the permafrost zone, it can increase permafrost carbon release by about $50 \%$. This concerning type of thaw, however, has not been accounted for in Earth-system models that are used to simulate the climate impacts of permafrost thawing.

It's not all bad news though. $\mathrm{CO}_{2}$ released from permafrost boosts the growth of vegetation in the broad permafrost zone, which can lead to more $\mathrm{CO}_{2}$ being removed from the atmosphere. This vegetation response is especially important when thawing is gradual, as models show that this $\mathrm{CO}_{2}$ fertilization effect can determine the overall net carbon balance in the northern permafrost region under warming conditions $s^{8}$. The regrowth of vegetation after ground slumping may also partly offset the climate impact, although the effect is estimated to be limited ${ }^{1}$. The enhanced carbon sequestration by vegetation provides an important mechanism to reduce the permafrost-climate feedback, yet its magnitude remains largely unknown.

Model simulations suggest that around 23-174 Pg of carbon may be released from the permafrost zone by 2100 under the Representative Concentration Pathway (RCP) 8.5 scenario, and 6-33 Pg C under RCP 4.5 (ref. ${ }^{7}$ ). To put these numbers into context, carbon emissions from fossil fuel use during 2009-2018 was estimated to be about 9.5 Pg of carbon each year?. Narrowing these estimates will depend on comprehensive integration of multiple complex, interlinked processes into these models. More measurements are needed throughout these different systems to understand the fate and distribution of the thawed carbon. Cross-community efforts will be critical to stitching together these processes into a well-developed framework, from which the overall carbon balance of thawing permafrost can be more precisely constrained.

Published online: 30 November 2020 https://doi.org/10.1038/s41561-020-00668-y

References

1. Turetsky, M. R. et al. Nat. Geosci. 13, 138-143 (2020).

2. Biskaborn, B. K. et al. Nat. Commun. 10, 264 (2019).

3. Plaza, C. et al. Nat. Geosci. 12, 627-631 (2019).

4. Vonk, J. E. \& Gustafsson, Ö. Nat. Geosci. 6, 675-676 (2013).

5. Zhang, L. et al. Nat. Geosci. 13, 349-354 (2020).

6. Turetsky, M. R. et al. Nature 569, 32-34 (2019).

7. Walter Anthony, K. et al. Nat. Commun. 9, 3262 (2018).

8. McGuire, A. D. et al. Proc. Natl Acad. Sci. USA 115, 3882-3887 (2018)

9. Friedlingstein, P. et al. Earth Syst. Sci. Data 11, 1783-1838 (2019). 